\title{
PROMPTS IN LECTURERS' LEARNING TO TEACH IN PRIVATE UNIVERSITIES IN KENYA
}

\author{
M. Omingo \\ School of Finance \\ Strathmore University \\ Nairobi, Kenya \\ e-mail: momingo@strathmore.edu
}

\section{ABSTRACT}

The overall aim of the study was to use Archer's morphogenetic approach to analyse how lecturers learn to teach in private universities in Kenya. In developing suitable academic development strategies, this approach can be useful in analysing the structural and cultural emergent powers and the emotions that prompt lecturers, in different contexts, to learn how to teach. Semistructured interviews were used to collect qualitative data from twenty-five lecturers who were purposively selected. The analysis indicated that the university's policy statements, the teaching and learning conditions and student composition presented structural and cultural limitations that lecturers had to respond to. Although their emergent structural and cultural powers prompted in lecturers a greater desire to learn to teach, the lecturers' experience of emotions such as worry, threat, curiosity and disappointment played a greater role.

Keywords: morphogenetic approach, learning to teach, emergent powers, emotions, prompts

\section{INTRODUCTION}

Today, lecturers work in a dynamic and super-complex world where the diversity of students' motivation and cultural and educational background makes teaching more demanding in terms of the preparation of learning material, motivation strategies and assessment (McLean 2006, 36). With many changes taking place in the learning environment, Pollard $(2010,5)$ asserts that lecturers are expected to possess a full repertoire of pedagogic options in order to create highachieving environments for the maximum number of diverse learners. Similarly, lecturers in private universities encounter large classes filled with students of various abilities and with different expectations. This means that lecturers cannot evade their responsibilities as educators, hence the need for continual professional development, which involves learning to teach in both formal and informal settings.

\section{THE SETTING OF THE STUDY}

The widespread demand for higher education in Kenya was triggered by the massive expansion 
of primary and secondary education, and the increasing sophistication of the economy, which demands a skilled workforce (Mwiria and Partnership for Higher Education in Africa 2007, 123). Due to the increase in the student population, there has been a proliferation of both public (government funded) and private universities (which receive no direct government support). In 1994 there were only four public universities and three accredited private universities. By June 2015 there were a total of 58 universities in Kenya, 22 public and 36 private. Seventeen of the private universities are chartered by the Commission of University Education (CUE) while 19 are unaccredited (CUE 2015).

Private universities in Kenya are sponsored by groups of individuals registered as companies or trusts (Mwiria and Partnership for Higher Education in Africa 2007, 124). They are mainly non-profit-making organisations catering for those students who do not meet government requirements for sponsorship in public universities. Some of them do not meet the admission grades, while others meet the grades but prefer programmes not offered in public universities. The majority of the students admitted to private universities in Kenya, unlike their counterparts in public universities, are not as academically motivated, as indicated by their relatively low academic grades. They are generally from more affluent socio-economic backgrounds (Mwiria and Partnership for Higher Education in Africa 2007, 147). Most private universities, in addition to the core courses in the degree programmes, also offer additional courses in mathematics, languages, accounting and basic computer skills to all students, irrespective of the degrees they are registered for (CUE 2015).

Unlike teachers in primary and secondary schools in Kenya, lecturers in higher education are not trained to teach (Wanzare and Ward 2000, 267). The few trained lecturers learnt their skills when they taught in secondary schools and not in institutions of higher education. They face challenges such as students' diversity, large classes and the demands of industry and the professions (Mwiti, Ngunjiri and Muchira 2009, 13). Unfortunately, while other students' learning issues are well spelt out in the institutions' policies, lecturers' learning to teach has been disregarded in national policies and in the planning of most institutions, as it is assumed that academic qualifications are sufficient (Oanda, Chege and Wesonga 2008, 12; Otiende 2006, 40). Day $(1999,15)$ points out that acquiring academic qualifications to become a teacher has always been necessary, but to succeed as a professional over a career span, academic qualifications alone are not adequate.

Given the above profile of higher education in Kenya, a one-size-fits-all academic development strategy for lecturers in private and public universities is not feasible. When lecturers commence their teaching careers, and later in their careers, they are likely to encounter 
learning and teaching environments that have been defined by structural and cultural factors that already exist, namely material resources and ideational conditions that are the bearers of causal powers (Archer 1995, 195). Given that conditions such as class size and students' abilities and capability are likely to be similar across the universities, a starting point in the development of appropriate programmes for lecturers in private universities in Kenya and elsewhere to learn teaching skills, could be to identify the structural and cultural emergent properties (SEPs and CEPs) and the emotions that prompt and challenge lecturers to learn to teach.

\section{STRUCTURAL AND CULTURAL CONDITIONING}

In this study, a morphogenetic approach (Archer 1995, 193) was employed to identify the structural and cultural conditions that pre-date lecturers' learning to teach in private universities. The approach deals with the 'before' at time one $\left(\mathrm{T}^{1}\right)$, 'during' $\left(\mathrm{T}^{2}-\mathrm{T}^{3}\right)$ and 'after' $\left(\mathrm{T}^{4}\right)$. This article concentrates on the 'before' $\left(\mathrm{T}^{1}\right)$ which is about conditioning. In the morphogenetic cycles, $\mathrm{T}^{1}$ is a $\mathrm{T}^{4}$ of previous cycles as 'structure and culture necessarily predate the actions which transform it, and, that structural elaboration is brought about by those actions' (Archer 1995, 168). In the structural and cultural morphogenetic cycles, the first phase is conditioning, which is about shaping the context through vested interests and the subsequent opportunity costs that may result in bonuses or penalties. Vested interests are means by which structural and cultural properties exert a conditional influence on subsequent action and are associated with a position (Archer 1995, 203-205). In the higher education sector, vested interest in the position of a lecturer could be to teach in such a way that students experience learning. The opportunity costs, or the value of the foregone benefit of not learning to teach could be effective teaching, effective assessment and feedback in relation to students learning; however, where lecturers do learn to teach, bonuses such as 'being rated highly by students' may result.

The structural and cultural emergent powers (SEPs and CEPs), and emotions elicited in lecturers by some of the SEPs and CEPs, only have a tendency to action. Archer $(1995,185-$ 190) describes SEPs as the material resources: their distributions, roles, institutional structures and social system; and CEPs as ideational. They do not determine people's actions and their effects may or may not be mediated through social agency (Archer 2003, 9). Lecturers may or may not want to learn in formal settings and/or engage with students and colleagues in informal settings, even after being potentially enabled or constrained. According to Archer $(1995,196)$ 'structural and cultural emergent properties are mediated to people and, 'work through the 
shaping of the situations in which they find themselves'. The morphogenetic task, therefore, is to supply an account of the objective conditions and the people's powers, and their interplay (Archer 1995, 201).

In this study, analysing prompts in lecturers' learning to teach was considered a starting point for understanding how lecturers learn to teach. This is in line with the assertion that to begin to understand any particular morphogenetic cycle 'it is necessary to begin with an examination of how things came to be’ (Quinn 2006, 26).

\section{METHODOLOGY}

An exploratory study was deemed appropriate in resolving the research problem, that is, how lecturers learn to teach in formal and informal settings. Exploratory research enabled the researcher to ask open-ended questions in order to understand the situation on the ground (Saunders 2012, 432). In this study, I asked open-ended questions to find out how lecturers learn to teach. It was important to do this, as what each person learns tends to be unique (Jordan 2008, 18).

The study was also explanatory, as one of its objectives was to establish the interplay, or the causal effects, within structure, culture and agency. Explanatory research was useful in examining the causation; that is, the interplay between the objective and subjective prompts. Sayer $(2010,105)$ explains causation, not as the number of times that something happens, but as 'explanation that depends on identifying causal mechanisms and how they work, and discovering if they have been activated under what conditions'.

The study adopted a critical realist approach: realistic where the systemic, structural and cultural conditions which have an influence on lecturers' learning, were viewed as having an independent reality. According to Maxwell $(2013,136)$, realism is 'the belief that there is a real world that exists independently of our perception and theories'. Thus objects have intrinsic properties, which are capable of generating an outcome and research is about discovering these properties and mechanisms that generate events. Critical realism views the mechanisms, events and experience as constituting three overlapping domains of reality: real, actual and empirical. The real refers to whatever exists, the structures and powers of objects, whether natural or social; the actual refers to what happens if and when those powers are activated or remain dormant; and finally, the empirical is defined as the domain of experiences (Sayer 2010, 12). Central to a realist approach to research is that it seeks to identify and explain the causal forces that operate at the deeper ontological levels of reality and to discover something about reality which is not yet known: in essence, to accept that things do not happen by chance or without 
reason (Sayer 2010, 5). The domain of the real is the most important as it encompasses the actual and the empirical domains. Thus, this study endeavours to analyse the underlying factors: the real structural and cultural powers and the emotions that prompt lecturers to learn to teach.

The target population comprised the directors of the teaching and learning centres and lecturers in private universities in Kenya. The participants in this study were lecturers from four private universities, fictionalised as ABC University, DJK University, MUN University, and TJR University. The reason for choosing private universities was that some of them had implemented programmes for lecturers to learn to teach, with the aim of ensuring that students got 'value for money'. In ABC and DJK Universities, for example, centres of learning and teaching conducted an Academic Staff Development Programme (ASDP) and Critical Reflective Thinking Programme (CRTP) respectively. In addition, some of the lecturers in the four selected universities had participated in the Post-graduate Certificate in Academic Practice Programme (PCAP) offered by York St John University in the United Kingdom.

A sample of 29 lecturers, including four directors, was used. The sample was considered adequate as the emphasis of the study was on gaining in-depth insights into what prompts lecturers to learn to teach. According to Given (2008, 827), the research goal for most qualitative studies is to emphasise an in-depth and highly contextualised understanding of specific phenomena, which makes them well-suited to small samples.

Purposive sampling was the main method employed. Snowball sampling was used in one university. Purposive sampling was applied to identify those lecturers who had attended a programme on learning how to teach. In this study, it was important to select participants with whom I could establish the most productive relationships and those who would assist me to best answer my research question. This was in line with Maxwell (2013, 97), who points out that 'selecting those times, settings and individuals that can provide you with information that you need to answer your research questions is the most important consideration in qualitative selection decisions'. In addition, some lecturers were likely to prefer to keep their teaching as a private activity rather than a public one. To make it public, I had to purposely select 'exemplary' lecturers who were eager to share what they were doing, unlike the 'less proficient' ones, who would have been justifiably concerned about revealing their inadequacies. This was also pointed out by Maxwell $(2013,199)$.

Table 1 shows the universities that participated and the number of lecturers that were interviewed. 
Table 1: Source of interviewees

\begin{tabular}{|l|l|}
\hline University & Number of Interviewees \\
\hline DJK & 4 \\
\hline MUN & 4 \\
\hline TJR & 4 \\
\hline ABC & 13 \\
\hline TOTAL & $\mathbf{2 5}$ \\
\hline
\end{tabular}

The data-collection method used was semi-structured interviews that lasted one hour on average. The questions that were asked were not predetermined. Most of the questions that I asked came from the interview notes that I drafted from their responses to the question of how they had grown as lecturers. To start the interview, I asked all the lecturers the same question about how they had learnt to teach (See Appendix 2).

The interviews provided an opportunity to probe the interviewees' responses for more explanations and to get more insight on some issues that were unclear. This probing added depth and significance to the data collected. Also, during the interviews, some respondents led the discussion into areas that I had not anticipated, providing more in-depth data and greater understanding of how lecturers learn to teach. In spite of the fact that some of respondents were likely to report what they wanted me to hear (Cousin 2009, 75), the interviews, and especially the probing that followed, gave them a chance to 'think aloud' about things that may not have occurred to them before. This enabled me to collect a rich and detailed set of data (Saunders 2012, 378) and provided the respondents with opportunities to tell their learning stories.

The interviews were recorded and notes were made as the interviews progressed. Making notes enabled me probe the interviewees on the key aspects discussed, providing me with more detailed explanations. Recording data allowed me to concentrate on questioning and listening to the interviewees, and also provided an accurate, permanent record (Saunders 2012, 396).

The interviews were later transcribed. I read all the transcriptions, paragraph by paragraph and line by line, thinking systematically about what each item of data was describing. The transcriptions were then coded using in vivo and initial coding. Saldaña $(2009,3)$ defines in vivo coding as the code that is taken directly from what is said. To analyse data I used tables, network views, reports and memos.

\section{PROMPTS IN LECTURERS' LEARNING TO TEACH}

The analysis showed that at time one $\left(\mathrm{T}^{1}\right)$ to present time $\left(\mathrm{T}^{2}\right)$, when lecturers begin to teach, they are prompted to learn by the socio-cultural powers emerging from structural conditions, such as university policy statements, teaching and learning conditions and the student 
composition.

The data showed that university policy statements pre-dated the lecturers' actions. Missions, visions and teaching philosophies of universities were likely to encourage lecturers to learn more about the university in formal professional development programmes where the lecturers are made aware of the existence of such policy statements. For example, Kal, a respondent, recalled how his vice-chancellor discussed the university's mission, vision and teaching philosophy during sessions of the Academic Staff Development Programme. Kal stated: 'I found it useful as I got to know more about the mission and the vision of the university. It made me more aware of the institution, the values and the history.' Shulman and Shulman (2004, 269) suggest that teachers learn and develop within a broader context of community. They argue that the teachers' vision, understanding, motivation and practice should be supported by the shared vision, knowledge base, commitment and the practice of the community.

The teaching and learning conditions in lecturers' workplaces also pre-dated the lecturers' actions. Some of the teaching and learning conditions that the respondents confronted were large classes. Jebu, another respondent, remarked how large classes were challenging and an impediment to students' learning. 'I have complained about the number of students in my classes. My main reason for complaining about the numbers is that I had about 170 students, and I think, for me, those are too many.' Although the large class was a concern to Jebu, she had no control over the student numbers in the class. Archer $(2003,135)$ notes that such a concern could lead Jebu to engage with its limitations; in this case, she could pursue a course of action such as attending a workshop on dealing with large classes, or engaging in conversations with colleagues, as suggested by Thomson $(2015,137)$.

In other instances, subjects such as law, accounting and finance are compulsory for technology students, for example. These subjects were a challenge as students either lacked the interest and/or the ability to learn them. For example, Bor, a respondent, explained that: 'Students tell me, "I do your subject because I have no option. It is a compulsory unit in the information technology programme. I do not know how it is going to help me become a better manager or leader".' Inter-disciplinary and multi-disciplinary programmes offered to students in the four universities pre-dated lecturers' teaching and were likely to affect their teaching. Similarly, a lecturer could be prompted and challenged to learn how to simplify complex learning material. Ramsden $(2003,95)$ points out that simplifying learning material and making learning interesting as one of the principles of effective teaching.

The student body was diverse in terms of learning needs, work experience, educational 
and cultural backgrounds. Kahe, a respondent, described student diversity thus: 'Any group of students is different from the others, like the cloud pattern in the morning and at midday'. One of the consequences of student diversity is that it places more responsibility on the lecturer to plan for uncertainty. Tas, for example, used case methodology but was unable to anticipate the direction his students' work experience would take the class discussions. This required him to think more carefully about what he did:

For example, there is a case that I have been using for many years but I still spend the same amount of time, 3-4 hours, preparing for the same session. Something I have been doing for the past 5 years because I don't know what to expect in the classroom. It will be a different group of highly experienced executives and they might be asking questions or saying something totally outside the case. (Tas)

Teaching highly experienced executives prompted Tas to think more carefully and critically about his students' learning. Learning situations tend to be unpredictable. In the case of Tas, such situations prompted him to plan for the uncertainty.

Students' different abilities were likely to prompt learning. What the students did and what they did not do (actions and reactions) tended to prompt the lecturers to learn to teach. For instance, a class of students with strong abilities prompted Luma to learn: 'They sit there, look at you and they listen and they take things very seriously. They don't laugh as easily. This forces me to think through things, raises the stakes. They grasp the concepts faster.' Although the lecturers who participated in this study identified socio-cultural conditions at $\mathrm{T}^{1}$ as external, these conditions were likely to shape the teaching and learning situations that they confronted, challenging them to learn in the process.

In this study, further analysis revealed that it was not the policy statements, teaching and learning conditions or student composition per se that prompted the lecturers, but the emergent properties. Archer $(1995,135)$ describes the causal powers of the parts as emerging. According to Archer $(1995,50)$, emergence implies a stratified social world including a non-observable world. 'It is about going beyond the empirical and actual world and analysing the deep level of reality’ (Sayer 2010, 87). Elder-Vass (2010, 23) explains emergence as a relationship between the properties of a whole and its parts in a particular moment of time. This study therefore went further and identified the emergent powers underlying the structural and cultural conditions that prompt lecturers to learn to teach. Archer $(1995,195)$ notes that the structural and cultural powers can exist unexercised as people are capable of resisting, suspending and circumventing structural and cultural tendencies. But the agential powers can also be suspended or modified by the SEPs and CEPs. The SEPs and CEPs must therefore be mediated by agential powers 
which act as mediators (Archer 1995, 196). The structural and cultural emergent powers and how they were mediated by agential powers are discussed in the next section.

\section{STRUCTURAL, CULTURAL AND PERSONAL EMERGENT POWERS}

The analysis showed that lecturers' awareness of students' other commitments, such as work, prompted some respondents to learn to teach, as they realised the consequences for the learning of the students concerned. Dia's comment, for example, indicated that her pragmatic motive for changing her practice was the need to maintain contact with students who found it difficult to attend tutorials. Becoming aware of other commitments that made students' miss classes prompted and challenged Dia to learn how to use the e-learning platform. 'Now I don't have to worry about those who have missed class. Especially for the evening students, some of them cannot make it to class because of work.'

The university policy statements did not prompt the lecturers to learn to teach, but a lecturer's motivation to ensure that his/her ethos and teaching approaches were congruent with the university's ethos and teaching philosophy was expressed by Luma: 'When I attended one of the sessions, I was more interested in the university’s ethos; does it match my philosophy?'. Crawford $(2010,196)$ points out that perceived incompatibility and lack of correlation between institutional and individual priorities can be constraining. However, in instances where they are facilitative, aligned and responsive, they generate enablements. Other emergent properties were the realisation that large classes were a limitation to students' learning, as in Jebu's case (described earlier) and the need to simplify complex ideas and motivate students in the interand multi-disciplinary programmes, as expressed by Bor:

I try to help the students get a different perspective. When I ask the same question at the end of the class, they appreciate and they are able to see that it has really made a big difference. In many cases, I try to use industry experience and to teach the students to captivate their attention to the subject. (Bor)

The encounters of lecturers with students of diverse educational and cultural backgrounds were also emergent properties that made lecturers think about their teaching:

I had never seen anybody react like that when I approached them in a friendly manner, trying to create a rapport between myself as the lecturer and the student and there was no response. That was a real shock to my system. (Neth)

What should be noted is that the prompting of the structural emergent powers and cultural emergent powers was not direct, but dependent on their reception and realisation by the 
lecturers. The motivation to align their priorities with those of the university, the awareness of students' work commitments and the encounters with students tended to prompt lecturers to learn how to teach. The emergent powers had an effect only when lecturers conceived of and pursued various courses of action that they cared about and upon which the emergent powers would impinge. For example, although the students’ work commitments could potentially have constituted a prompt to action, they only influenced Dia, for example, when she got worried about students' absenteeism. She became aware of the likely consequences, such as students failing, and this influenced her course of action, so that she learnt how to use the e-learning platform:

In 2010 I attended the first ASDP, the one for June and I think during the same year I attended the one for three months; the short course. That helped a lot as at least, I was able to know about the e-learning and actually got to using it because I never used to use e-learning at all. Even I used to wonder how it fits in our school. (Dia)

The considerable range of abilities within classes due to students' work or industry experience, could also have constituted a prompt, but had a notable effect only when Tas viewed the students' work experiences as a threat. The realisation that the learning situation was unpredictable, especially when using case methodology, made him plan for uncertainty.

Students' educational backgrounds were also identified as a factor. Students with strong abilities had an effect only when the lecturers encountered a group that surprised and/or interested them. This was mediated in one instance by the lecturer's plan to use a reflective journal. The students' actions challenged Luma to document her reflections-in-action: 'Now I am going to start a reflective journal with this particular group because they have taught me'. Neth also made an effort to learn more about the students’ culture in general:

I thought a lot about that experience (asked students a question and did not receive any response) and realised that there are many cultural issues here that I don't know about, but need to learn about in order to be able to reach out to the students. Informally I could ask colleagues and friends: Why did this kind of reaction happen when I was asking with an innocent intent? (Neth)

In the cases described above, although the emergent powers motivated the lecturers, the role that the exercise of personal emergent powers played, especially in evoking emotional responses, was also significant. Archer $(1995,253)$ points out that it is 'equally important to recognise that the self-same sequence by which agency brings about social and cultural transformation is simultaneously responsible for the systematic transforming of social agency itself'. Archer $(2003,118)$ defines agents as 'collectivities sharing the same life-chances', and points out that agents 'do have interests (in improving or protecting the latter) which are 
external to the roles yet can be pursued through them'. Agents from the morphogenetic perspective are 'agents of something. They are agents of socio-cultural system and equally of systemic features they transform' (Archer 1995, 257). Lecturers' agency prompted their learning through their actions in the workplace, shaping the situations they involuntarily confronted, which is in line with Archer's argument $(1995,247)$ that 'as human beings we have powers/properties that lead to structural/cultural elaboration that are elaborated in the process'.

Lecturers were emotional about students' learning. Emotions such as anxiety and happiness seemed to have played a role in lecturers' learning to teach. According to Archer (2000, 241), emotions foster our commitments but do not determine them. Archer $(2000,195)$ defines emotions as 'commentaries upon our concerns' that are elicited by significant events. Events are significant when they touch upon one or more concerns of the subject (Archer 2000, 204). In this study, evidence suggested that the encounters with students, the teaching of large classes and the learning about the university policy statements were some of the significant events or critical incidents that elicited emotions in lecturers.

At classroom level, the encounters with students of different educational and cultural backgrounds prompted and challenged lecturers to learn to teach. However, it was emotions like curiosity, fascination, joy and disappointment that tended to prompt action. Curiosity about their students prompted lecturers to learn as expressed by Luma. This relates to what Archer (2000, 206) explains about the effect of congruence or incongruence between people's expectations and experiences. In situations where lecturers' expectations and experiences were incongruent, as in Luma's case, they tended to learn as 'the high intensity end of emotion was activated' (Archer 2000, 207).

At faculty/departmental level, the need to simplify complex ideas and motivate students in the inter- and multi-disciplinary programmes prompted and challenged lecturers to learn to teach. However, it was the emotion of hope on the part of the lecturer, elicited by students' negative attitudes towards a subject, that prompted the lecturer to learn how to simplify complex problems: 'The person organising PCAP sent an email inviting us to join training ... I sent an email back to be one of the participants ... I want to see someone change. I want to see that negative attitude has changed.' (Kahe).

At the institutional level, the established evaluative standards, such as students' rating of courses, also elicited emotions. According to Archer $(2000,218)$ 'well established standards are evaluative standards but their effect is dependent upon our feeling bad if we fall short of them and good if we live up to them'. In line with this view, Gel, a respondent, was happy when students rated her highly but noted the need to continue learning to teach, saying, 'The 
evaluation in subject X was good. Out of 5 the rating was over 4 . I want to do more because I should never be complacent ...'. Gel's assertion of complacency was in line with Archer's $(2003,109)$ observation that 'emotions cannot be said to ensure satisfaction but are plans and readiness for ensuring satisfaction'. However, some lecturers were disappointed, as the ratings did not reflect the effort they had invested in the course. '... In their feedback it was a bit interesting, they did not rate me very highly, I think the average was 3.5 out of 5 and I was a bit disappointed because I had put a lot of effort into it' (Neth). Thus, both positive and negative feedback elicited emotions.

In this study, emotions were brought to the fore when lecturers expressed what they cared about most. Lecturers were joyful when students' opinions of their teaching were positive and also when students effectively learned their subject. '... It gives me great joy to see someone who is not able to speak a language and then they start speaking' (Rau). The same emotions of joy or disappointment prompted them to learn to teach in cases where students' opinion about how effectively they performed their job mattered to them.

Although emotions such as anxiety, uncertainty and surprise prompted lecturers to learn to teach in formal and informal learning settings, their emotions only prompted them when their teaching was a matter of concern to them. Lecturers' learning was mediated by their agency to learn how to use the e-learning platform, to plan extensively and purposefully and to maintain a reflective journal. This affirms the trajectory of concerns becoming projects and then practices (Archer 2003, 135).

\section{CONCLUSION}

In this study I have attempted to analyse the underlying emergent structural and cultural properties that prompt lecturers to learn to teach in private universities in Kenya. I found confirmation of the role emotions play in motivating lecturers to extend their teaching skills. A one-size-fits-all academic development strategy is unlikely to work in cases where conditions external to lecturers and beyond their control and emotions, as analysed in this study, are not considered. It is important for academic developers to take account of the potential prompts to action in place to determine where to start with academic development. Moreover, lecturers are differentially situated in terms of the material resources available in universities and faculties and therefore specific institutional research is necessary on academic development (Quinn 2012, 47). It is useful if this research is underpinned by an understanding of the interplay of structure, culture and agency in these situations.

The lecturers who were interviewed for this study tended to care about students' learning 
and were therefore motivated to learn to teach. Where the lecturers' emotions are not elicited and the effects of the structural and cultural emergent powers are not significant to them, very little or no learning is likely to take place. According to Archer (2003, 6), people possess the intentionality to define and design courses of action in order to achieve their own ends. Some lecturers may not perceive the above structural and cultural emergent powers as prompts and do not respond to them by taking steps to learn. In such cases, they are likely to forego benefits such as effective teaching, effective assessment and feedback methods and personal and professional growth. Analysing the conditions in different universities is likely to be an appropriate strategy to attract lecturers to attend various academic staff development programmes. In such instances, the programmes will take the lecturers' individual needs into consideration.

The analysis of structural and cultural properties that prompt and challenge lecturers to learn to teach is important in developing a contextual approach to lecturers' learning to teach. It is the exercise of personal powers that is important in progressing the morphogenetic cycle. Further investigation into the exercise of personal emergent powers such as self-consciousness, self-commitment and self-monitoring could result in a richer explanation of how lecturers learn to teach.

\section{REFERENCES}

Archer, M. S. 1995. Realist social theory: The morphogenetic approach. Cambridge and New York: Cambridge University Press.

Archer, M. S. 2000. Being human: The problem of agency. Cambridge and NewYork: Cambridge University Press.

Archer, M. S. 2003. Structure, agency, and the internal conversation. Cambridge and New York: Cambridge University Press.

Cousin, G. 2009. Researching learning in higher education. Oxon: Routledge.

Crawford, K. 2010. Influences on academics' approaches to development: Voices from below. International Journal for Academic Development 15(3): 189-202.

Commission of University Education. 2015. Accreditation and programmes offered in universities in Kenya. www.cue.or.ke (accessed 15 June 2015).

CUE see Commission of University Education.

Day, C. 1999. Developing teachers: The challenges of life-long learning. London: Routledge Falmer.

Elder-Vass, D. 2010. The causal power of social structures: Emergence, structure and agency. Cambridge and New York: Cambridge University Press.

Given, L. M., ed. 2008. The Sage encyclopedia of qualitative research methods. Sage Publications, Los Angeles, California.

Jordan, A. 2008. Approaches to learning: A guide for teachers. Maidenhead: Open University Press.

Maxwell, J. A. 2013. Qualitative research design: An interactive approach. 3rd Edition. Thousand Oaks, Ca: Sage Publications. 
McLean, M. 2006. Pedagogy and the university: Critical theory and practice. London and New York: Continuum.

Mwiria, K. and Partnership for Higher Education in Africa, eds. 2007. Public and private universities in Kenya: New challenges, issues and achievements. Oxford and Nairobi: James Currey and East African Educational Publishers.

Mwiti, F., I. Ngunjiri and C. Muchira. 2009. Final destination study to determine the relevance of Strathmore University degrees to market needs in Kenya. Unpublished paper.

Oanda, O., F. Chege and D. Wesonga. 2008. Privitisation and private higher education in Kenya. Dakar: CODESRIA.

Otiende, J. 2006. Institutional transformations and implications for access and quality in public and private universities in Kenya. Journal of Higher Education Africa 3: 37-44.

Pollard, A. 2010. Professionalism and pedagogy: A contemporary learning opportunity. A commentary by TLRP and GTCE. London: TLRP.

Quinn, L. 2006. A social realist account of the emergence of a formal academic staff development programme at a South Africa University. Unpublished PhD thesis. Rhodes University.

Quinn, L. 2012. Re-Imagining academic staff development: Spaces for disruption. Stellenbosch: SUN MeDia.

Ramsden, P. 2003. Learning to teach in higher education. $2^{\text {nd }}$ Edition. London: Routledge-Falmer.

Saldaña, J. 2009. The coding manual for qualitative researchers. Los Angeles, Ca: Sage.

Saunders, M. 2012. Research methods for business students. 6th Edition. Harlow and New York: Pearson.

Sayer, R. A. 2010. Method in social science: A realist approach. Rev. 2nd Edition. London and New York: Routledge.

Shulman, L. S. and J. H. Shulman. 2004. How and what teachers learn: A shifting perspective. Curriculum Studies 36: 257-271.

Thomson, K. 2015. Informal conversations about teaching and their relationship to a formal development program: Learning opportunities for novice and mid-career academics. International Journal for Academic Development 20(2): 137-49.

Wanzare, Z. and L. K. Ward. 2000. Rethinking staff development in Kenya: Agenda for the twenty-first century. International Journal of Educational Management 14(6): 265-75. 


\section{Appendix 1: List of Participants}

\begin{tabular}{|c|c|c|c|}
\hline Participant & University & Gender & Department/Faculty \\
\hline P1: Luma & $A B C$ & $\mathrm{~F}$ & Humanities \\
\hline P2: Jebu & $A B C$ & $\mathrm{~F}$ & Humanities \\
\hline P3: Kal & $A B C$ & $\mathrm{M}$ & Commerce \\
\hline P4: Raka & $A B C$ & $\mathrm{~F}$ & Commerce \\
\hline P5: Neth & $A B C$ & $\mathrm{~F}$ & Humanities \\
\hline P6: Gel & $A B C$ & $\mathrm{~F}$ & Commerce \\
\hline P7: Bor & $A B C$ & M & Commerce \\
\hline P8: Riso & $A B C$ & M & Mathematics \\
\hline P9: Sey & DJK & $\mathrm{F}$ & Communication \\
\hline P10: Dref & TJR & $\mathrm{M}$ & Languages \\
\hline P11: Mij & $\mathrm{TJR}$ & $M$ & Information Technology \\
\hline P12: Jos & TJR & $M$ & Psychology \\
\hline P13: Tas & $\mathrm{ABC}$ & $\mathrm{M}$ & Information Technology \\
\hline P14: Eca & DJK & $\mathrm{F}$ & Communication \\
\hline P15: Mao & MUN & $\mathrm{F}$ & Humanities \\
\hline P16: Demu & $\mathrm{ABC}$ & $\mathrm{M}$ & Information Technology \\
\hline P17: Rau & $A B C$ & M & Languages \\
\hline P18: Ane & MUN & $\mathrm{F}$ & Counseling \\
\hline P19: Nep & DJK & $\mathrm{M}$ & Engineering \\
\hline P20: Rasa & TJR & $\mathrm{F}$ & Education \\
\hline P21: Daw & $A B C$ & $\mathrm{M}$ & Hospitality and Tourism \\
\hline P22: Dia & $\mathrm{ABC}$ & $\mathrm{F}$ & Accountancy \\
\hline P23: Romu & $A B C$ & $\mathrm{~F}$ & Commerce \\
\hline P24: Kahe & MUN & $\mathrm{M}$ & Mathematics \\
\hline P25: Theo & DJK & $M$ & Communication \\
\hline
\end{tabular}

\section{Appendix 2}

\section{Letter to potential respondents, explaining the purpose and scope of the research}

'I have been working with lecturers on their learning (professional growth) since 2007. In 2009/2010, I coordinated the Postgraduate Certificate Programme (PCAP) offered by York St Johns University in UK to thirty-five participants from five Kenyan universities. I would like to find out how useful PCAP has been in your teaching and how you continue learning to teach. I have also been conducting a two week Academic Staff Development Programme (ASDP) for lecturers in my university since 2009 and short courses over a period of three months (For those from other universities, I mentioned what had been happening in their universities in terms of lecturers' learning to teach). The question that some lecturers asked after the training was, what next? This made me think of finding out what lecturers do after the training and how the lecturers' learning to teach can be sustained in their workplaces? All that you need to tell me is how you have grown as a lecturer over the years.' 